\title{
Türkiye'deki Bir Üniversite Eğitim ve Araştırma Hastanesinde Elde Edilen Toksijenik Clostridioides difficile İzolatlarına Antimikrobiyallerin İn Vitro Etkisi
}

\author{
In Vitro Activities of Antimicrobials Against Toxigenic \\ Clostridioides difficile Isolates Obtained in a University Training \\ and Research Hospital in Turkey
}

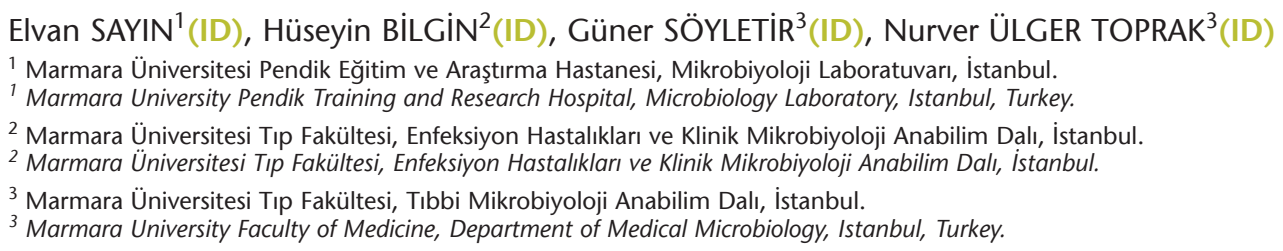

* Bu çalışma, Marmara Üniversitesi Bilimsel Araştırma Projeleri Komisyonu Başkanlığı tarafından SAG-C-TUP-110915-0424 numaralı proje ile desteklenmiştir.

Makale Atıfı: Sayın E, Bilgin H, Söyletir G, Ülger Toprak N. Türkiye'deki bir üniversite eğitim ve araştırma hastanesinde elde edilen toksijenik Clostridioides difficile izolatlarına antimikrobiyallerin in vitro etkisi. Mikrobiyol Bul 2020;54(3):368-377.

\section{ÖZ}

Zorunlu anaerop, gram-pozitif sporlu bir basil olan Clostridioides difficile, eski taksonomiye göre Clostridium difficile, antibiyotik ilişkili diyarenin en önemli etkenidir. C.difficile enfeksiyonları birçok ülke için önemli bir sağlık problemi halini almıştır. Dünya genelinde antibiyotiklere dirençli C.difficile izolatlarının oranı hızla artmaktadır. Ancak bu konuda ülkemize ait sınırlı veri bulunmaktadır. Bu çalışmada Marmara Üniversitesi Pendik Eğitim ve Araştırma Hastanesi Mikrobiyoloji Laboratuvarına gönderilmiş dışkı örneklerinde üretilen C.difficile izolatlarının antibiyotiklere duyarlılık profillerinin belirlenmesi amaçlanmıştır. Serolojik ve moleküler yöntemlerle toksijenik olduğu saptanan toplam 93 C.difficile izolatı çalışmaya alınmıştır. İzolatların antibiyotik duyarlılık paternleri "Clinical and Laboratory Standards Institute (CLSI; M11-A7)" önerileri doğrultusunda agar dilüsyon yöntemiyle belirlenmiştir. C.difficile enfeksiyonlarının tedavisinde öncelikle tercih edilen antimikrobiyaller ile birlikte geçmiş epidemiyolojik çalışmalarda yer alan toplam 12 antibiyotik (metronidazol, vankomisin, meropenem, seftriakson, ampisilin-sulbaktam, klindamisin, eritromisin, moksifloksasin, tetrasiklin, doksisiklin, tigesiklin ve linezolid) test edilmiştir. Minimum inhibitör konsantrasyonu (MiK) değerleri "European Committee on Antimicrobial Susceptibility Testing (EUCAST)" tarafından önerilen sınır değerlere göre yorumlanmıştır. EUCAST rehberinde sınır değerleri bulunmayan seftriakson, klindamisin, tetrasiklin ve moksifloksasin için CLSI tarafından önerilen sınır değerler dikkate alınmıştır. EUCAST ve CLSı rehberlerinde sınır değerleri bulunmayan linezolid, eritromisin, doksisiklin için MiK $_{50}$ ve MiK $_{90}$ değerleri belirlenmiştir. İzolatların tamamı metronidazol, vankomisin, ampisilin-sulbak- 
tam, tetrasiklin ve meropeneme duyarlı bulunmuştur. Seftriakson, klindamisin ve moksifloksasine duyarlılık ise sırasıyla \%58.1, \%35.5 ve \%20.4 oranlarında saptanmıştır. Mik ${ }_{50}$ ve MiK ${ }_{90}$ değerleri tigesiklin, eritromisin, linezolid, doksisiklin için sırasıyla 0.125-0.25 mg/L, 1-2 mg/L, 2-2 mg/L, 0.062-0.125 mg/L olarak tespit edilmiştir. Bu çalışma, hastanemizdeki C. difficile izolatlarının antimikrobiyal duyarlılık paternlerini göstermesinin yanı sıra, ülkemizde rutin uygulamada anaerobik kültür ve antibiyotik duyarlıık testlerinin çalışıımadığı klinik mikrobiyoloji laboratuvarları için de veri kaynağı olacaktır. Sonuç olarak, C.difficile enfeksiyonlarının tedavisinde yaygın kullanılan iki ana antibiyotik ilacın; metronidazol ve vankomisinin etkili olduğu görülmektedir. Bununla birlikte, test edilen diğer bazı antibiyotiklere karşı yüksek direnç varıı̆ı, direnç gelişimini yakından takip etmek için sürveyans çalışmalarının gerekliliğini ortaya koymaktadır.

Anahtar kelimeler: Clostridioides difficile; antibiyotik duyarlılk; metronidazol; vankomisin.

\section{ABSTRACT}

Clostridioides difficile, a gram-positive, anaerobic, spore forming bacillus known as Clostridium difficile according to the previous taxonomy, is the most important agent of antibiotic-associated diarrhea. C.difficile infections have become a major health problem for many countries. The rate of antimicrobial resistant C.difficile isolates is rapidly increasing all around the world. Yet there is limited data on this subject in our country. The aim of this study was to determine the antimicrobial susceptibility profiles of C.difficile strains isolated from stool samples in Marmara University Pendik Training and Research Hospital Microbiology Laboratory. A total of 93 toxigenic C.difficile, defined by serological and molecular techniques, were included in this study. Antimicrobial susceptibility profiles of isolates were determined by using agar dilution method according to the Clinical and Laboratory Standards Institute (CLSI; M11-A7). The following antimicrobials commonly used for the treatment of C.difficile infections or applied previously in C.difficile epidemiological studies were tested: metronidazole, vancomycin, meropenem, ceftriaxone, ampicillin-sulbactam, clindamycin, erythromycin, moxifloxacin, tetracycline, doxycycline, tigecycline and linezolid. The minimum inhibitory concentration (MIC) results were interpreted according to the breakpoints described by the European Committee on Antimicrobial Susceptibility Testing (EUCAST). Breakpoints recommended by CLSI were applied for ceftriaxone, clindamycin, tetracycline and moxifloxacin since there were no EUCAST breakpoints for these antimicrobials. $\mathrm{MIC}_{50}$ and $\mathrm{MIC}_{90}$ values were determined for three antimicrobials (linezolid, erythromycin, doxycycline) whose breakpoints were not described by EUCAST or CLSI guidelines. All isolates were susceptible to metronidazole, vancomycin, ampicillin-sulbactam, meropenem and tetracycline. Susceptibility to ceftriaxone, clindamycin and moxifloxacin was found in $58.1 \%, 35.5 \%$ and $20.4 \%$ of the isolates, respectively. $\mathrm{MIC}_{50}$ and $\mathrm{MIC}_{90}$ values of tigecycline, erythromycin linezolid, doxycycline were $0.125-0.25 \mathrm{mg} / \mathrm{L}, 1-2 \mathrm{mg} / \mathrm{L}, 2-2 \mathrm{mg} / \mathrm{L}, 0.062$ $0.125 \mathrm{mg} / \mathrm{L}$, respectively. This study shows the current antimicrobial susceptibility patterns of C.difficile isolates in our hospital and will also be the reference data for clinical laboratories in our country where anaerobic culture and susceptibility tests are not performed in routine practice. In conclusion, two main antimicrobial agents commonly used in the treatment of C.difficile infections, metronidazole and vancomycin, seem to be effective. However, high resistance rates against to the certain tested antimicrobials highlight the need for further surveillance to monitor the emergence of resistance.

Keywords: Clostridioides difficile; antimicrobial susceptibility; metronidazole; vancomycin

\section{Gíriş}

Clostridioides difficile, eski adlandırmaya göre Clostridium difficile, antibiyotik ilişkili diyare (AiD)'nin en önemli ve en sık rastlanan etkenidir. Toksijenik C.difficile izolatlarıyla kolonize olmuş, çoğunlukla antimikrobiyal ilaç kullanımı ile bağırsak mikrobiyotası bozulmuş hastalarda kendiliğinden iyileşen diyareden, yaşamı tehdit eden psödomembranöz kolit, toksik megakolon ve bağırsak perforasyonuna kadar değişen klinik tablolar gelişebilmektedir ${ }^{1}$.

Enfeksiyonların patogenezinde, bakteri tarafından üretilen toksin A ve toksin B büyük rol oynamaktadır ${ }^{2}$. Ayrıca son yıllarda, Kanada, Amerika Birleşik Devletleri (ABD) ve bir- 
çok Avrupa ülkesinde, virülansı yüksek yeni C.difficile izolatlarına (varyant toksin veya binary toksin üreten) bağlı AiD epidemileri tanımlanmıştır. Virülansı yüksek ribotip 027 ve 078 izolatlarının daha ağır seyirli, tekrarlayan ve ölümcül enfeksiyonlara neden oldukları saptanmıştır. Antibiyotik direnci bu epidemiyolojik değişikliklerin ve yeni tiplerin ortaya çıkmasında önemli paya sahiptir. Geçmişteki endemik durumlarda klindamisine dirençli izolatlar başrolü oynarken, günümüzde C.difficile enfeksiyonlarında florokinolonlara dirençli yeni tiplerin öne çıktığı gözlenmektedir. Florokinolonların yoğun kullanılmasının bu antibiyotiklere karşı direnç kazanan C.difficile ribotip 027 ve 078 suşlarının ortaya çıkmasını ve yayıımasını kolaylaştırdığı varsayılmaktadır ${ }^{3,4}$. C. difficile enfeksiyonlarının standart antimikrobiyal ilaç tedavisinde ilk seçenek metronidazol veya vankomisindir ${ }^{4}$. Genel olarak bu antibiyotiklerle yapılan tedaviler başarıı sonuç vermektedir, ancak bazı ülkelerde metronidazole dirençli, vankomisine ise azalmış duyarlılık gösteren C.difficile izolatlarının varlığı gösterilmiştir ${ }^{6,7}$. C. difficile'nin dirençli olduğu antibiyotiklerin kullanımı çoklu antibiyotik ilaç direnci gösteren izolatların seçilmesini kolaylaştırmaktadır. Epidemik suşların çok sayıda antibiyotiğe direnç gösteriyor olmaları, bunlara bağlı enfeksiyonların tedavisinde zorlukların yaşanmasına neden olmaktadır ${ }^{5}$. Başarııı bir tedavinin gerçekleştirilebilmesi için etken C.difficile izolatlarının duyarlıık profilinin bilinmesi gereklidir.

Ülkemizde çok az sayıda laboratuvarda rutin olarak C.difficile kültürü yapılmaktadır, dolayısıyla bu mikroorganizmaların antibiyotiklere duyarlııkları konusunda ülkemize ait çok az veri bulunmaktadır ${ }^{8-10}$. C. difficile izolatlarının duyarlııklarını tespit etmek için agar dilüsyon yöntemi referans yöntemdir. Günlük laboratuvar işleyişinde uygulanması pek mümkün olmayan bu yöntem daha çok epidemiyolojik veri elde etmek amacıyla kullanılmaktadır. Hastalardan izole edilen patojenler toplanarak belli zaman aralıklarında duyarlııklarının çalışııması önerilmektedir ${ }^{11}$.

Bu çalışmada, Marmara Üniversitesi Pendik Eğitim ve Araştırma Hastanesinde dört yılda üretilmiş patojen toksijenik C. difficile izolatlarının çeşitli antibiyotiklere duyarlııklarının belirlenmesi amaçlanmıştır.

\section{GEREÇ ve YÖNTEM}

Bu çalışma, Marmara Üniversitesi Tıp Fakültesi Klinik Araştırmalar Etik Kurulu onayı ile gerçekleştirildi (Tarih: 01.09.2015 ve Karar no: 70737436-050.06.04).

\section{Clostridioides difficile İzolatları}

Bu çalışmaya, 2012-2016 yılları arasında Marmara Üniversitesi Pendik Eğitim ve Araştırma Hastanesi Mikrobiyoloji Laboratuvarına dışkıda toksin varlığının test edilmesi amacıyla gönderilen veya dışkı kültürü öncesinde yapılan mikroskobik incelemede lökosit görülen klinik örneklerden elde edilen toksijenik C.difficile izolatları dahil edildi. Aynı dönem içinde aynı hastaya ait birden fazla dışkı örneğinde üreyen izolatlardan yalnız biri çalışmaya alındı. íki yaş altındaki hasta örneklerinden elde edilen izolatlar çalışma dışında bırakıldı. İzolatlar "Skim milk" besiyerinde $-80^{\circ} \mathrm{C}$ 'de saklandı. 
Dışkı örnekleri doğrudan ve alkol şok işlemi uygulandıktan sonra sikloserin-sefoksitin-fruktoz agara (CCFA; BioMerieux, Fransa) ekilerek anaerop ortamda 48 saat süreyle inkübe edildi. Elde edilen zorunlu anaerop bakteriler VITEK MS ${ }^{\circledR}$ (bioMerieux, Fransa) sistemiyle tanımlandı. C.difficile olarak tanımlanan izolatlar beyin-kalp-infüzyon sıvı besiyerine (BHIB; Becton Dickinson, Almanya) ekilerek, anaerop ortamda beş gün inkübe edildikten sonra 3000 rpm'de 20 dakika santrifüj edildi ve üst sıvısı alınarak toksin varlığı VIDAS C.difficile Toxin A \& B (BioMerieux, Fransa) kiti ile araştırıldı.

İzolatların DNA izolasyonu, Brucella agardaki taze kültürden "Ultraclean ${ }^{\mathrm{TM}}$ microbial DNA izolasyon kiti (Qiagen, Almanya)" ile gerçekleştirildi. Toksin A, toksin B ve "binary" toksin genleri, özgül primerler kullanılarak polimeraz zincir reaksiyonu (PCR) yöntemiyle araştırıldı $^{8}$ (Tablo I). Pozitif kontrol olarak toksin A ve B için C.difficile NCTC 11223 izolatı; binary toksin için C.difficile HU 10010 izolatı kullanıldı.

\section{Antibiyotik Duyarlılık Testleri}

Serolojik testle pozitif bulunan, toksin A ve toksin B genlerine sahip olduğu, binary toksin geni barındırmadığı saptanan izolatlara antibiyotik duyarlılık testi uygulandı. "Clinical and Laboratory Standards Institute (CLSI)" ve "The European Committee on Antimicrobial Susceptibility Testing (EUCAST)" önerileri doğrultusunda 12 antibiyotik; metronidazol, vankomisin, meropenem, seftriakson, ampisilin-sulbaktam, moksifloksasin, klindamisin, eritromisin, linezolid, tigesiklin, tetrasiklin ve doksisiklin olarak seçildi. CLSI (M11-A7) önerileri doğrultusunda; hemin, K vitamini ve \%5 koyun kanı bulunduran Brucella agar kullanılarak agar dilüsyon yöntemi uygulandı. Taze kültürden 0.5 McFarland bulanıklığında hazırlanan bakteri süspansiyonu 1/10 oranında seyreltilerek antibiyotik içeren Brucella agara ekildi ve plaklar anaerobik ortamda $37^{\circ} \mathrm{C}^{\prime}$ de 48 saat inkübe edildi. İnkübasyon sonrası üremenin inhibe olduğu en düşük konsantrasyon minimum inhibitör konsantrasyonu (MiK) değeri olarak kabul edildi ${ }^{11}$. İzolatların antibiyotiklere duyarlılık durumu EUCAST klinik sınır değerlerine göre yorumlandı ${ }^{12}$. EUCAST klinik sınır değeri bulunmayan antibiyotikler için CLSI sınır değerleri kullanıldı. EUCAST ve CLSI'nın

Tablo I. C.difficile Toksin Genlerine Özgül Primerler ve Reaksiyon Koşulları

\begin{tabular}{|c|c|c|c|c|}
\hline \multicolumn{2}{|c|}{ Primer } & \multirow{2}{*}{$\begin{array}{l}\text { DNA dizisi } \\
\text { 5'-GGAAGAAAAGAACTTCTGGCTCATCAGGT-3' }\end{array}$} & \multicolumn{2}{|c|}{ Reaksiyon koşulları } \\
\hline$T c d A$ & $\mathrm{R}$ & & $95^{\circ} \mathrm{C}^{\prime}$ de $20 \mathrm{sn}$ & \multirow{4}{*}{35 döngü } \\
\hline$T c d A$ & Fw & 5'-CССAATAGAAGATTCAATATTAAGCTT-3' & $56^{\circ} \mathrm{C}^{\prime}$ de $2 \mathrm{dk}$ & \\
\hline$T c d B$ & $\mathrm{R}$ & 5'-CAC TTA GCT CTT TGA TTG CTG CAC CT-3' & $72^{\circ} \mathrm{C}^{\prime} \mathrm{de} 1 \mathrm{dk}$ & \\
\hline$T c d B$ & Fw & 5'-GTG TAG CAA TGA AAG TCC AAG TTT ACG C-3' & $74^{\circ} \mathrm{C}^{\prime}$ de $5 \mathrm{dk}$ & \\
\hline$C d t A$ & $\mathrm{R}$ & 5'-AGG ATT ATT TAC TGG ACC ATT TG-3' & \multirow{4}{*}{$\begin{array}{l}94^{\circ} \mathrm{C}^{\prime} \text { de } 45 \mathrm{sn} \\
52^{\circ} \mathrm{C}^{\prime} \text { de } 1 \mathrm{dk} \\
75^{\circ} \mathrm{C}^{\prime} \text { de } 80 \mathrm{sn}\end{array}$} & \multirow{4}{*}{35 döngü } \\
\hline$C d t A$ & Fw & 5'-TGA ACC TGG AAA AGG TGA TG-3' & & \\
\hline$C d t B$ & $\mathrm{R}$ & 5'-AAC GGA TCT CTT GCT TCA GTC-3' & & \\
\hline$C d t B$ & Fw & 5'- CTT AAT GCA AGT AAA TAC TGA G-3' & & \\
\hline
\end{tabular}


sınır değer bildirmediği ancak direnç profili epidemiyolojik açıdan önem arz eden üç antibiyotik (linezolid, eritromisin, doksisiklin) için $\mathrm{MiK}_{50}$ ve $\mathrm{MiK}_{90}$ değerleri belirlendi. Antibiyotik duyarlılık yöntemi sırasında pozitif kontrol olarak Bacteroides fragilis ATCC 25285 kullanıldı.

\section{İstatistiksel Analiz}

Yaş gruplarına (3-17 yaş, 18-64 yaş, 65 yaş ve üstü) göre antibiyotiklerin (moksifloksasin, klindamisin ve seftriakson) duyarlılık oranlarını değerlendirmek için üçten fazla bağımsız değişkenin karşılaştırıldığı analizde Kruskal Wallis varyans testi kullanıldı.

\section{BULGULAR}

Bu çalışmaya, dört yıllık zaman diliminde uygun dışkı örneklerinden izole edilen, toksijenik olduğu belirlenmiş olan, ayrıca aynı hastaya ait örneklerden izole edilen ancak izolasyon tarihleri arasında iki ay ya da daha fazla zaman farkı bulunan üç hastaya ait ikişer izolatın çalışmaya dahil edilmesi nedeniyle, toplam 90 hastadan elde edilen 93 toksijenik C.difficile izolat alınmıştır.

Çocuk yaş grubundaki hastaların \%47.7 ( $n=21)^{\prime}$ si kız, \%52.3 ( $\left.n=23\right)^{\prime}$ ü erkek; erişkin yaş grubunda ise \%58.7 ( $n=27)^{\prime}$ si kadın, \%41.3 ( $\left.n=19\right)^{\prime}$ ü erkek olarak belirlenmiştir.

C. difficile izolatlarının \%19.4 ( $n=18)^{\prime}$ ü poliklinik, \%80.6 ( $\left.n=75\right)^{\prime}$ sı ise yatan hastalardan elde edilmiştir. Yaş gruplarına göre hastaların dağılımları incelendiğinde izolatların 47 (\%50.5)'si çocuk, 27 (\%29)'si 18-64 yaş grubu erişkin hastalardan, 19 (\%20.5)'u ise 65 yaş ve üstü erişkin hastalardan üretilmiştir.

Çalışmaya dahil edilen tüm izolatlar $(n=93)$ metronidazol, vankomisin, ampisilinsulbaktam, tetrasiklin ve meropeneme duyarlı bulunmuştur. Klindamisin, seftriakson ve moksifloksasine ise önemli oranda direnç tespit edilmiş, bu antibiyotiklere duyarlılık oranları sırasıyla, \%35.5, \%58.1 ve \%20.4 olarak bulunmuştur.

EUCAST ve CLSI'da sınır değer bildirilmeyen antibiyotiklerden tigesiklin, eritromisin, linezolid ve doksisiklin için MiK $_{50}$ ve MiK $_{90}$ değerleri sırasıyla, 0.125 ve $0.25 \mathrm{mg} / \mathrm{L}, 1$ ve $2 \mathrm{mg} / \mathrm{L}, 2$ ve $2 \mathrm{mg} / \mathrm{L}, 0.062$ ve $0.125 \mathrm{mg} / \mathrm{L}$ olarak saptanmıştır. Test edilen 93 izolatın antibiyotik duyarlılıkları Tablo II'de gösterilmiştir.

En fazla direnç saptanan üç antibiyotiğe (seftriakson, moksifloksasin ve klindamisin) duyarlılık oranları, yaş gruplarına göre incelendiğinde gruplar arasında istatistiksel olarak anlamlı fark görülmemiştir.

\section{TARTIŞMA}

Bu çalışmada dört yıllık bir zaman diliminde laboratuvarımızda elde edilmiş toksijenik C.difficile izolatlarının antibiyotik duyarlılıkları saptanmıştır. İzolatlarımızın tamamı C.difficile enfeksiyonlarının tedavisinde kullanılan ilk seçenek antibiyotikler olan metronidazol veya vankomisine duyarlı bulunmuştur. Klindamisin, seftriakson ve moksifloksasine ise önemli oranda direnç saptanmıştır. Moleküler test sonuçlarına göre izolatlarımızın 


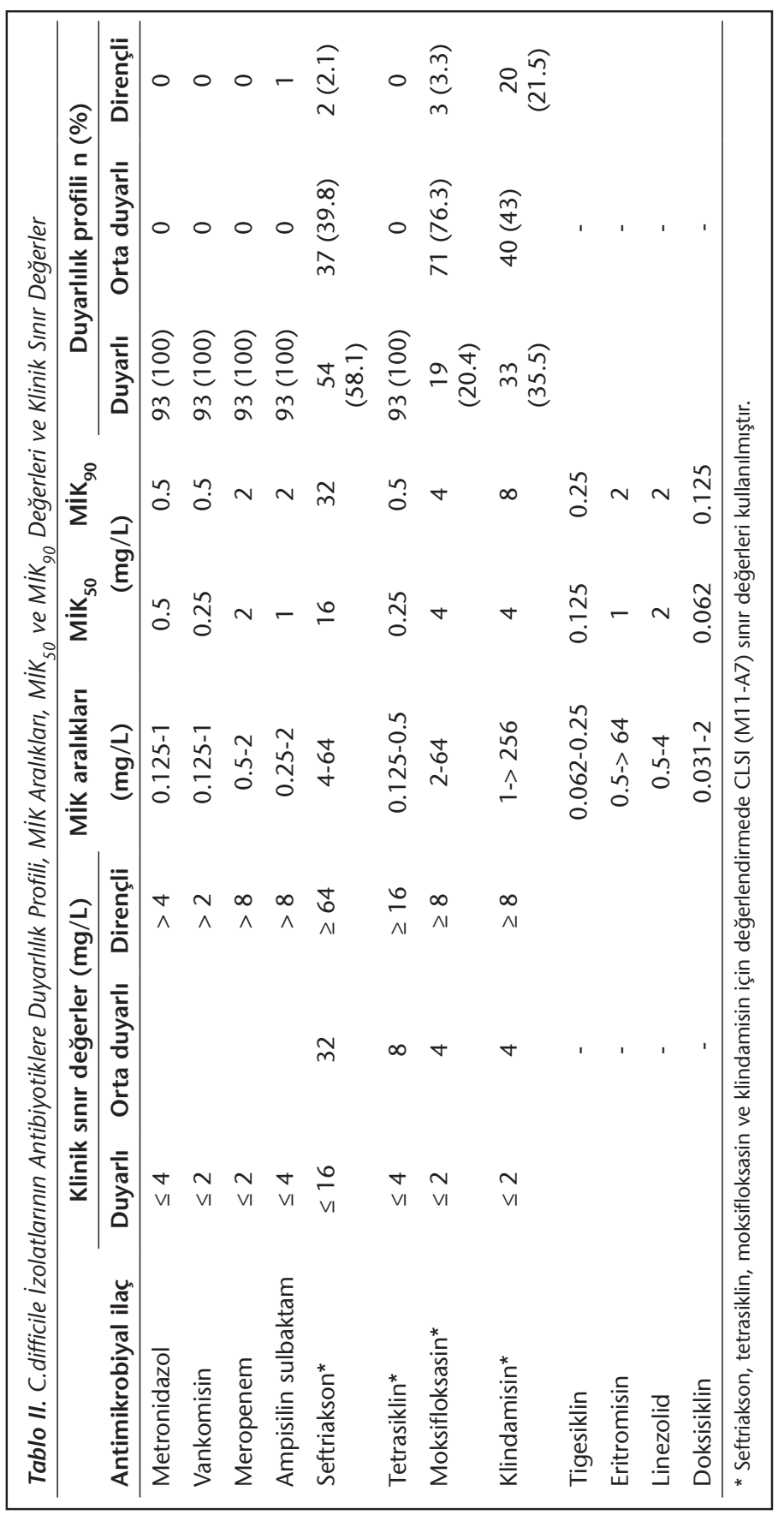


hepsinde toksin A ve toksin B genleri tespit edilmiş, hiçbirinde binary toksin genlerine rastlanmamıştır.

Dünya genelinde C.difficile izolatlarının antibiyotiklere direnç oranları, coğrafi bölgelere, yerel veya ulusal antimikrobiyal uygulama politikalarına bağlı olarak merkezlere, kullanılan test yöntemine göre farklılıklar göstermektedir. Ülkemizde anaerop bakterilerin antibiyotiklere duyarlılık durumları çok az merkezde çalışılmaktadır ${ }^{9,10}$. Dolayısıyla sonuçlarımızı kıyaslayabilmek için fazla veriye ulaşılamamıştır.

Hafif ve orta derece C.difficile enfeksiyonlarının tedavisinde ilk seçilen antimikrobiyal metronidazoldür ${ }^{13}$. Birçok ülkede C.difficile izolatlarının tamamının metronidazole duyarlı olduğu bildirilmiştir ${ }^{14-16}$. Diğer yandan metronidazol tedavisine klinik yanıtsızlık gösteren olgular olmuş, bazı in vitro çalışmalarda dirençli izolatlar saptanmıştır. ABD'de 271 izolatla yapılan bir araştırmada \%13.3 oranında direnç, İran'da 75 izolatla yapılan bir çalışmada ise \%5.3 oranında direnç tespit edilmiştir ${ }^{6,17}$. Çalışmamızda izolatlarımızın tamamı metronidazole duyarlı ve MiK değerleri ECOFF (2 mg/L) değerinin altında bulunmuştur. Bu sonuç hastanemizde metronidazolün C.difficile enfeksiyonlarında güvenle kullanılabileceğini göstermektedir.

Benzer şekilde izolatlarımız, C.difficile enfeksiyonlarının tedavisinde sık kullanılan bir diğer antimikrobiyal vankomisine de \%100 oranında duyarlı ve Mik değerleri ECOFF (2 $\mathrm{mg} / \mathrm{L}$ ) değerinin altında bulunmuştur. Dünya genelinde yapılan çalışmalar vankomisinin C.difficile izolatlarına etkili olduğunu göstermektedir. Ancak, özellikle Doğu Asya ülkelerinde vankomisine azalmış duyarlıık profiline sahip suşlar (MiK aralığı > 2-16) bildirilmiş$\operatorname{tir}^{7,18}$. Adler ve arkadaşlarının İsrail'de yaptığı çalışmada ise 65 adet ribotip 027 izolatından 57'sinin vankomisine azalmış duyarlılık gösterdiği saptanmıştır ${ }^{19}$.

Çalışmamızda meropenem tüm izolatlar üzerine dar $\mathrm{MiK}_{50}-\mathrm{MiK}_{90}$ aralığıyla etkili bulunmuştur (Tablo II). Farklı araştırmalarda da meropenemin C.difficile izolatları üzerinde etkili olduğu gösterilmiş, sınırlı sayıda dirençli izolat saptanmıştır20,21.

Metronidazol, vankomisin ve meropenem duyarlılık sonuçlarımız, 2008-2010 yılları arasında hastanemizde izole edilen C.difficile izolatları ile yapılan çalışma sonuçlarıyla benzer bulunmuştur ${ }^{9}$. Her iki çalışmada, belirtilen antibiyotiklere \%100 oranında duyarlılık saptanmıştır ancak MiK $_{50}$ ve $\mathrm{MiK}_{90}$ değerlerinde çalışmalar arasında farklılıklar gözlenmiştir. Metronidazol için $0.125 \mathrm{mg} / \mathrm{L}$ olan $\mathrm{MiK}_{50}$ değeri ve $0.25 \mathrm{mg} / \mathrm{L}$ olan $\mathrm{MiK}_{90}$ değerlerinin her ikisi de $0.5 \mathrm{mg} / \mathrm{L}^{\prime}$ ye yükselmiştir. Vankomisin için ise $0.5 \mathrm{mg} / \mathrm{L}$ ve $1 \mathrm{mg} / \mathrm{L}$ olan MiK $_{50}$ ve MiK ${ }_{90}$ değerleri birer dilüsyon azalarak 0.25 mg/L ve 0.5 mg/L'ye inmiştir. Meropenemin ise MiK $_{90}$ değeri aynı kalırken, MiK $_{50}$ değeri bir dilüsyon artmıştır ${ }^{9}$. İzolatlarımızın metronidazol ve meropenem Mik değerlerindeki artışı az oranda olmakla birlikte, hastanemizde bu antibiyotiklerin sık kullanılıyor olması bakterilerimizdeki duyarlılık profilinde zaman içinde değişimlerin olabileceği izlenimi vermektedir, bu da duyarlıık durumlarının yakından izlenmesini gerekli kılmaktadır. 
Klindamisin, sefalosporinler ve daha yakın zamanda florokinolonların kullanılmasının C.difficile enfeksiyonu gelişmesinde diğer antibiyotiklere göre daha fazla risk oluşturduğu gösterilmiştir ${ }^{3,5}$.

Klindamisin kullanımının C.difficile enfeksiyonu gelişmesinde önemli bir risk faktörü olduğunun anlaşıldığı 1970'lerden bu yana, klindamisine dirençli C.difficile izolatlarına bağlı birçok salgın gerçekleşmiştir ${ }^{22,23}$. ABD ve Avrupa'da klindamisin kullanımını kontrol etmek için antimikrobiyal yönetim politikaları uygulanmış, zaman içinde klindamisin ile ilişkilendirilen C.difficile enfeksiyonu oranında azalma sağlanmış olmakla birlikte C.difficile izolatlarında \%55'lere varan oranda direnç bildirilmiştir ${ }^{5,24}$. Çalışmamızda klindamisine duyarlı olmayan izolatlarımızın oranı \%64.5 olarak bulunmuştur. Bu sonuç, hastanemizde 2008-2010 yılları arasında elde edilen C.difficile izolatlarındaki \%62'lik orana göre daha yüksek saptanmıştır? 9

Sefalosporinlerin 1980-1990 yıllarında hastanelerde sık kullanılmasıyla C.difficile enfeksiyonlarında artış gözlenmiştir. Avrupa genelinde hastalardan izole edilen C.difficile izolatlarının ortalama \%51'inde, Japonya'da \%49'unda, Avustralya'da ise \%86'sında sefalosporinlere direnç bildirilmiştir ${ }^{20,25}$. Çalışmamızda izolatlarımızın yarısından azı, \%41.9'u, seftriaksona duyarlı bulunmuştur.

İzolatlarımızın sadece \%20.4'ü moksifloksasine duyarlı bulunmuştur. Yüksek MiK (4 mg/L) değeriyle moksifloksasinin hastanemiz izolatlarına etkisiz olacağı öngörülebilir. Dünya genelinde florokinolonlara direnç yüksektir; siprofloksasine \%99, moksifloksasin ve dördüncü kuşak florokinolonlara ise \%47'leri aşan oranda direnç bildirilmiştir. 2000 'li yıllarda bu grup antibiyotiklere gelişen direnç, ribotip 027 C.difficile izolatına bağlı C.difficile enfeksiyonlarının ortaya çıkması ve giderek artan insidansıyla paralel gerçekleşmiştir. Almanya ve Fransa'da yapılan çalışmada moksifloksasine direnç oranı \%68 bulunmuştur $^{26}$. Polonya'da ise binary toksin üreten 027 ve 176 ribotiplerinden oluşan 17 izolatın tamamında moksifloksasine direnç saptanmıştır ${ }^{27}$. İzolatlarımızın binary toksin genine sahip olmaması sevindirici olmakla birlikte, $\% 80$ 'e varan oranda moksifloksasine duyarlı olmayan izolatın var olması ileride bu tür virülan ve dirençli bakterilerle gelişecek C.difficile enfeksiyon sıklığının yüksek olacağını düşündürmektedir.

EUCAST rehberinde tigesiklin, doksisiklin, eritromisin ve linezolide ait MiK sınır değerleri verilmemiştir. Sonuçlarımız dirençli veya duyarlı şeklinde yorumlanamamıştır, ancak ileride yapılacak çalışmalara ışık tutması, zaman içinde gelişebilecek Mik değişiklikleri veya MiK kaymasını göstermesi açısından MiK $_{50}$ ve MiK $_{90}$ değerleri verilmiştir. İzolatlarımızın tamamı ampisilin-sulbaktama duyarlı bulunmuştur, sonuçlarımız ülkemizde ve yurt dışında yapılan çalışma verileriyle uyumluluk göstermektedir ${ }^{9,28}$. Tetrasikline $\% 100$ duyarlııı oranıyla farklı ülkelerde yapılan çalışma verilerine (\%2-41 direnç) göre daha iyi bir konumda bulunmaktayız ${ }^{7,23}$.

Sonuç olarak, çalışmamızda C.difficile enfeksiyonlarına yol açan izolatlar toksin A ve toksin B genlerine sahip bulunmuştur. Virülansı yüksek binary toksin geni taşıyan suşlar saptanmamıştır. İzolatlarımızın C.difficile enfeksiyonları tedavisinde öncelikli olarak 
kullanılan metronidazol ve vankomisine duyarlı olması yüz güldürücüdür. Meropenem, ampisilin-sulbaktam ve tetrasikline izolatlarımızın hepsi dar MiK aralıklarıyla duyarlı bulunmuştur. Ancak, klindamisin, seftriakson ve moksifloksasine ise yüksek oranda direnç saptanmıştır. Bu durum herhangi bir nedenle bu antibiyotiklerin kullanılması halinde bağırsak mikrobiyotasının zarar görebileceği, toksijenik C.difficile izolatlarının baskın hale gelerek C.difficile enfeksiyonları oluşturabileceği intimalini akla getirmektedir. İzolatlarımızın yaklaşık \%80'inin moksifloksasine duyarlı olmaması virülan ve dirençli organizmaların gelecekte önemli problem oluşturacağı kaygısını yaratmaktadır. Bu durum, C.difficile izolatlarımızın duyarlıık profillerinin yakından izlenmesini gerekli kılmaktadır.

\section{TEŞEKKÜR}

C.difficile HU 10010 izolatının temini için Prof. Dr. E. Nagy (Szeged Üniversitesi, Klinik Mikrobiyoloji Enstitüsü, Macaristan)'e teşekkür ederiz.

\section{ETIK KURUL ONAYI}

Bu çalışma, Marmara Üniversitesi Tıp Fakültesi Klinik Araştırmalar Etik Kurulu onayı ile gerçekleştirildi (Tarih: 01.09.2015 ve Karar no: 70737436-050.06.04).

\section{ÇIKAR ÇATIŞMASI}

Yazarlar bu makale ile ilgili herhangi bir çıkar çatışması bildirmemişlerdir.

\section{KAYNAKLAR}

1. Lawson PA, Citron DM, Tyrrell KL, Finegold SM. Reclassification of Clostridium difficile as Clostridioides difficile (Hall and O'Toole 1935) Prévot 1938. Anaerobe 2016; 40: 95-9.

2. Kılıç A. Clostridium difficile enfeksiyonu: epidemiyoloji, risk faktörleri, patogenez, klinik özellikler, tanı ve tedavi. Mikrobiyol Bul 2013; 47(3): 556-66.

3. Schäffler H, Breitrück A. Clostridium difficile- from colonization to infection. Front Microbiol 2018; 646(9): $1-12$.

4. McDonald LC, Diekema DJ. Point-counterpoint: active surveillance for carriers of toxigenic Clostridium difficile should be performed to guide prevention efforts. J Clin Microbiol 2018; 56(8): e00782-18.

5. Spigaglia P. Recent advances in the understanding of antibiotic resistance in Clostridium difficile infection. Ther Adv Infect Dis 2016; 3(1): 23-42.

6. Norman K, Scott H, Harvey R, Norby B, Hume M. Comparison of antimicrobial susceptibility among Clostridium difficile isolated from an integrated human and swine population in Texas. Foodborne Pathog Dis 2014; 11: 257-64.

7. Dong D, Zhang L, Chen X, Jiang C, Yu B, Wang X, et al. Antimicrobial susceptibility and resistance mechanisms of clinical Clostridium difficile from a Chinese tertiary hospital. Int J Antimicrob Agents 2013; 41(1): 80-4.

8. Deniz U, Ülger N, Aksu B, Karavuş M, Söyletir G. Marmara Üniversitesi Hastanesi'nde yatan ishalli hastalardan izole edilen Clostridium difficile kökenlerinde toksin genlerinin araştırılması. Mikrobiyol Bul 2011; 45(1): 1-10.

9. Ülger N, İlki A, Akgül Ö, Söyletir G. Marmara Üniversitesi Hastanesinde izole edilen Clostridium difficile kökenlerinin antimikrobiyallere direnç durumu. MÜSBED 2011; 1(3): 162-5.

10. Salman E, Levent B, Karahan ZC. Toksin pozitif Clostridium difficile izolatlarının antimikrobiyal duyarlılıklar ve moleküler karakterizasyonu: Türkiye'den hipervirülan suşların varlığı ile ilişkili ilk bildirim. Mikrobiyol Bul 2017; 51(3): 236-46. 
11. Clinical and Laboratory Standards Institute. Methods for Antimicrobial Susceptibility Testing of Anaerobic Bacteria, Approved Standards-7 ${ }^{\text {th }}$ Edition, M11-A7, CLSI, Pennsylvania, USA, 2007.

12. The European Committee on Antimicrobial Susceptibility Testing. Breakpoint tables for interpretation of MICs and zone diameters. Version 7.1, 2017. http://www.eucast.org.

13. Debast S, Bauer M, Kuijper E. European Society of Clinical Microbiology and Infectious Diseases: update of the treatment guidance document for Clostridium difficile infection. Clin Microbiol Infect 2014; 20(Suppl 2): 1-26.

14. Chatedaki C, Voulgaridi I, Kachrimanidou M, Hrabak J, Papagiannitsis CC, Petinaki E. Antimicrobial susceptibility and mechanisms of resistance of Greek Clostridium difficile clinical isolates. J Glob Antimicrob Resist 2019; 16: 53-8.

15. Putsathit $P$, Maneerattanaporn M, Piewngam P, Knight DR, Kiratisin P, Riley TV. Antimicrobial susceptibility of Clostridium difficile isolated in Thailand. Antimicrob Resist Infect Control 2017; 8(6): 58.

16. Kociolek LK, Gerding DN, Osmolski JR, Patel SJ, Snydman DR, McDermott LA, et al. Differences in the molecular epidemiology and antibiotic susceptibility of Clostridium difficile isolates in pediatric and adult patients. Antimicrob Agents Chemother 2016; 60(8): 4896-900.

17. Goudarzi M, Goudarzi H, Alebouyeh M, Azimi Rad M, Shayegan Mehr FS, Zali MR, et al. Antimicrobial susceptibility of Clostridium difficile clinical isolates in iran. Iran Red Crescent Med J 2013; 15(8): 704-11.

18. Chia J, Lai H, Su L, Kuo A, Wu T. Molecular epidemiology of Clostridium difficile at a medical center in Taiwan: persistence of genetically clustering of $A-B+$ isolates and increase of $A+B+$ isolates. PLoS One 2013; 8(10): e75471.

19. Adler A, Miller-Roll T, Bradenstein R, Block C, Mendelson B, Parizade M, et al. A national survey of the molecular epidemiology of Clostridium difficile in Israel: the dissemination of the ribotype 027 strain with reduced susceptibility to vancomycin and metronidazole. Diagn Microbiol Infect Dis 2015; 83(1): 21-4.

20. Kuwata Y, Tanimoto S, Sawabe E, Shima M, Takahashi Y, Ushizawa H, et al. Molecular epidemiology and antimicrobial susceptibility of Clostridium difficile isolated from a university teaching hospital in Japan. Eur J Clin Microbiol Infect Dis 2015; 34(4): 763-72.

21. Hecht DW, Galang MA, Sambol SP, Osmolski JR, Johnson S, Gerding DN. In vitro activities of 15 antimicrobial agents against 110 toxigenic Clostridium difficile clinical isolates collected from 1983 to 2004. Antimicrob Agents Chemother 2007; 51(8): 2716-9.

22. Bartlett JG, Onderdonk AB, Cisneros RL, Kasper DL. Clindamycin-associated colitis due to a toxin-producing species of Clostridium in hamsters. J Infect Dis 1977; 136(5): 701-5.

23. Boyanova L, Kolarov R, Mitov I. Recent evolution of antibiotic resistance in the anaerobes as compared to previous decades. Anaerobe 2015; 31: 4-10.

24. Tenover FC, Tickler IA, Persing DH. Antimicrobial-resistant strains of Clostridium difficile from North America. Antimicrob Agents Chemother 2012; 56(6): 2929-32.

25. Knight D, Giglio S, Huntington P, Korman T, Kotsanas D, Moore C. Surveillance for antimicrobial resistance in Australian isolates of Clostridium difficile, 2013-2014. Int J Antimicrob Chemother 2015; 70: $2992-9$.

26. Reil M, Hensgens M, Kuijper E, Jakobiak T, Gruber H, Kist M, et al. Seasonality of Clostridium difficile infections in Southern Germany. Epidemiol Infect 2012; 140: 1787-93.

27. Woszczatynskia PO, Lachowicz D, Schneiderb A, Molb A, Pawlowskac J, Milked OE, et al. Occurrence of Clostridium difficile PCR-ribotype 027 and it's closely related PCR-ribotype 176 in hospitals in Poland in 20082010. Anaerobe 2014; 28: 13-7.

28. Kim H, Jeong SH, Roh KH, Hong SG, Kim JW, Shin MG, et al. Investigation of toxin gene diversity, molecular epidemiology, and antimicrobial resistance of Clostridium difficile solated from 12 hospitals in south Korea. Korean J Lab Med 2010; 30(5): 491-7. 